\title{
Bronchial wall parameters on CT in healthy never-smoking, smoking, COPD, and asthma populations: a systematic review and meta-analysis
}

\author{
Ivan Dudurych $^{1} \cdot$ Susan Muiser ${ }^{2}$. Niall McVeigh ${ }^{3}$ - Huib A.M. Kerstjens ${ }^{2} \cdot$ Maarten van den Berge $^{2}$. \\ Marleen de Bruijne ${ }^{4,5} \cdot$ Rozemarijn Vliegenthart $^{1}$ (D)
}

Received: 16 August 2021 / Revised: 14 December 2021 / Accepted: 29 January 2022 / Published online: 22 February 2022

(C) The Author(s) 2022

\begin{abstract}
Objective Research on computed tomography (CT) bronchial parameter measurements shows that there are conflicting results on the values for bronchial parameters in the never-smoking, smoking, asthma, and chronic obstructive pulmonary disease (COPD) populations. This review assesses the current $\mathrm{CT}$ methods for obtaining bronchial wall parameters and their comparison between populations.

Methods A systematic review of MEDLINE and Embase was conducted following PRISMA guidelines (last search date 25th October 2021). Methodology data was collected and summarised. Values of percentage wall area (WA\%), wall thickness (WT), summary airway measure (Pi10), and luminal area (Ai) were pooled and compared between populations.

Results A total of 169 articles were included for methodologic review; 66 of these were included for meta-analysis. Most measurements were obtained from multiplanar reconstructions of segmented airways (93 of 169 articles), using various tools and algorithms; third generation airways in the upper and lower lobes were most frequently studied. COPD $(12,746)$ and smoking $(15,092)$ populations were largest across studies and mostly consisted of men (median $64.4 \%$, IQR $61.5-66.1 \%$ ). There were significant differences between populations; the largest WA\% was found in COPD (mean SD $62.93 \pm 7.41 \%, n=6,045$ ), and the asthma population had the largest Pi10 $(4.03 \pm 0.27 \mathrm{~mm}, n=442)$. Ai normalised to body surface area (Ai/BSA) $\left(12.46 \pm 4 \mathrm{~mm}^{2}\right.$, $n=134$ ) was largest in the never-smoking population.

Conclusions Studies on CT-derived bronchial parameter measurements are heterogenous in methodology and population, resulting in challenges to compare outcomes between studies. Significant differences between populations exist for several parameters, most notably in the wall area percentage; however, there is a large overlap in their ranges.

Key Points

- Diverse methodology in measuring airways contributes to overlap in ranges of bronchial parameters among the neversmoking, smoking, COPD, and asthma populations.

- The combined number of never-smoking participants in studies is low, limiting insight into this population and the impact of participant characteristics on bronchial parameters.

-Wall area percent of the right upper lobe apical segment is the most studied (87 articles) and differentiates all except smoking vs asthma populations.
\end{abstract}

Keywords Tomography, X-ray computed $\cdot$ Review, Systematic $\cdot$ Adults $\cdot$ Bronchi $\cdot$ Pulmonary Disease, Chronic Obstructive

Rozemarijn Vliegenthart r.vliegenthart@umcg.nl

1 Department of Radiology, EB49, University Medical Centre Groningen, University of Groningen, Hanzeplein 1, 9700RB, Groningen, The Netherlands

2 Department of Pulmonology, University Medical Centre Groningen, University of Groningen, Groningen, The Netherlands
3 Department of Cardiothoracic Surgery, St. Vincent's University Hospital, Dublin, Ireland

4 Department of Radiology and Nuclear Medicine, Biomedical Imaging Group Rotterdam, Erasmus MC, Rotterdam, The Netherlands

5 Department of Computer Science, University of Copenhagen, Copenhagen, Denmark 


$\begin{array}{ll}\text { Abbreviations } \\ \text { Ai } & \text { Luminal area } \\ \text { BSA } & \text { Body surface area } \\ \text { COPD } & \text { Chronic obstructive pulmonary disease } \\ \text { CT } & \text { Computed tomography } \\ \text { FWHM } & \text { Full-width half-maximum } \\ \text { Pi10 } & \begin{array}{l}\text { Square root of the wall area of a hypothetical air- } \\ \text { way with internal perimeter of } 10 \mathrm{~mm}\end{array} \\ \text { QCT } & \text { Quantitative computed tomography } \\ \text { WA\% } & \text { Wall area percentage } \\ \text { WT } & \text { Wall thickness }\end{array}$

\section{Introduction}

Smoking, chronic obstructive pulmonary disease (COPD), and asthma are some of the top non-infective pulmonary health burdens in developed countries [1-3]. Due to an aging population and global smoking rates among others, the number of adults affected with COPD is expected to rise in the future. Both asthma and COPD have a wide variety of phenotypes and presentations, and all have in common the presence of airway inflammation and remodelling $[4,5]$.

Airway inflammation and remodelling can be measured on CT scans of the thorax. While progress in quantitative CT (QCT) has been made over the past couple of decades, there are many different parameters to evaluate airway disease [6]. Some recent advances have been made in the use of CT-derived bronchial parameters for monitoring disease trajectory, smoking cessation, genetic diversity, and treatment response [7-12]. These demonstrate the potential for quantification and characterisation of a diseased airway.

Current research in this field describes conflicting results for bronchial parameters. Some existing articles describe no differences between groups like lung cancer patients versus healthy individuals, smoking COPD patients versus smoking, and asthma patients versus controls [13-17], while others show significant differences between subgroups, such as COPD GOLD I-IV patients, that would enable further clinical applications like disease monitoring and identification of distinct groups within a population [18-22]. Additionally, some authors report that bronchial parameters vary by sex, age, and other characteristics [23-26], whereas this is not observed by others $[27,28]$. To explore this, we conducted a systematic review of bronchial parameter values in never-smoking, smoking, COPD, and asthma populations and compared the resulting pooled values between these populations.

Studies assessing bronchial parameters use a wide range of CT scanning protocols, reconstruction algorithms, and post-processing tools. This may have an impact on radiologic measurements. To enable the possibility of comparing novel research to past studies, we aimed to identify a most used reference technique for bronchial parameter measurement; thus, this review also summarises the current methodologies in use for determining bronchial parameters on CT scans in the neversmoking, smoking, COPD, and asthma populations. We identified previous general reviews on the subject of methodology in bronchial parameter measurement [29]; however, to the best of our knowledge, there are no previous systematic reviews of this subject involving review of the never-smoking population and pooling of neversmoking bronchial parameter data from multiple studies to enable comparison with other populations.

\section{Methods}

This study was conducted following Preferred Reporting Items for Systematic Reviews and Meta-analyses (PRISMA) [30]. The entirety of the screening process was performed using Covidence [31].

\section{Search strategy}

Medline and EMBASE were systematically searched. The last search date was 25/10/2021. The search strings encompassed the key words and index/Mesh terms related to the population: adult, smoking, never-smoking, COPD, asthma, the Intervention: computed tomography scan, and the Outcomes: bronchial wall measurements (e.g. wall measurement, lumen area, wall area etc.). The full search strings are provided in the supplemental material.

\section{Inclusion/exclusion criteria}

The following criteria were required for an article to be included: (1) original empirical research; (2) study population: adults $\geq 18$ years old and a focus on at least one of four target populations encompassing common respiratory states: never-smoking or smoking population (without pulmonary disease based on spirometry and GOLD criteria and no history of other pulmonary disease such as pulmonary fibrosis), COPD population, or asthma population; (3) study includes inspiratory chest CT scan for bronchial measurements; (4) research article must be peer-reviewed, English text available.

Exclusion criteria applied were as follows: (1) review article without new experimental data; (2) outlier study population, e.g. coal miners, World Trade Centre firemen; (3) article describing study on phantom/animal/histology specimen only; (4) < 50 participants in the study; (5) non-volumetric CT scan. A scan was considered non-volumetric if the slice 
increment exceeded slice thickness and was $>2$ times larger than voxel size.

The results of the search were processed for eligibility in two steps. Titles and Abstracts were screened by one author for inclusion in full text screening. This was followed by two of three researchers (I.D., S.M., N.McV.) screening the full text for eligibility in the review. Consensus between the two researchers was necessary for inclusion; if consensus could not be reached, the conflict was resolved by the third author. All researchers were blinded to decisions made by one another to reduce bias in the selection process.

Studies included in the methodological systematic review were excluded from the meta-analysis if they had insufficient data for pooling of bronchial parameters.

\section{Data extraction}

Methodologic and study data were collected when available. We focused on tools and methods used in measuring the bronchial walls. These were as follows: reconstruction used for measurement, whether bronchial parameters were normalised to other measurements, e.g. body surface area (BSA), the studied airway branches and generations, and the algorithms and software used for measurement (Figure S1). Following the exclusion of studies with insufficient data for pooling, for each population, we pooled bronchial parameters that were present in two or more of the included studies. These were the following: 3rd generation airway wall area percentage (WA\%), wall thickness (WT), luminal area (Ai), Ai normalised to BSA (Ai/BSA), and square root of the wall area of a theoretical airway with an internal perimeter of $10 \mathrm{~mm}$ (Pi10) (Figure S2). When multiple articles related to the same bronchial parameters/participants, those articles were grouped by their study name. Per study, data from the article with the largest cohort was used for analysis.

Articles that were eligible for inclusion in pooling of parameters were assessed for bias using a modified Cochrane Risk of Bias tool (RoB 2) [32]. In short, articles were evaluated for Low/High or Some Concerns bias in the domains of Sequence Generation, Allocation Concealment, Incomplete Outcome Data, Selective Outcome Reporting and Other Sources of Bias. A judgement of "High" in any of those domains marks a study as high risk of bias. Irrespective of bias, the reported mean and standard deviation of a bronchial parameter was extracted and included in pooled analysis.

\section{Statistical analysis}

Means and standard deviations from multiple studies were extracted and combined using the Cochrane formula for pooling groups [33]. The resulting pooled values were analysed using one-way ANOVA and Tukey-Kramer HSD post hoc test [34]. An additional meta-analysis of mean differences of COPD vs controls (never-smokers or smokers) for 3rd generation WA\% was performed using an inverse-variance with a random effects model, assuming heterogeneity (Deeks and Higgins 2010). To assess for publication bias, a funnel plot was graphed and Eggar's test performed [35]. A $p$ value of $<0.05$ was considered statistically significant.

\section{Results}

The search yielded 7,494 articles of which 2,719 were duplicates. Full-text screening was conducted on 375 articles resulting in 169 articles that were included for methodologic evaluation, a summary is provided in supplemental material Table S1. Of these, 66 were eligible for pooling of data, and for comparison of population groups (Figure 1). The most common source of bias was Low, with "Some Concerns" in the "Other" category due to study participants consisting mostly of men (Figure 2). The details of bias assessment are provided in the supplemental material Table S2.

\section{Systematic review-population}

We calculated the number of subjects in the four groups and per bronchial parameter measured (Figure 3). Among the reviewed studies, COPD and smoking populations had the largest number of participants: in WA\% $(n=11,839$ COPD and 9,257 smoking) and Pi10 ( $n=12,746$ COPD and 15,092 smoking). Across all measured parameters apart from Di, never-smoking had the lowest numbers of participants. Most of the COPD and smoking participants were men (64.41\% male [61.5-66.1\%] median [IQR]), while the asthma and never-smoking populations had more women than men (56.44\% female [54.7-58.6\%]) (Table 1).

\section{Methodologic review-image analysis methods}

We identified a wide range of methods used to obtain bronchial parameter measurements. Ninety-three of the 169 articles obtained measurements from a reconstructed plane perpendicular to the centreline of the airway, 29/169 articles measured airways cut in cross section on axial slices. 36/169 articles normalised one or more bronchial parameters to body surface area (BSA) or square root of BSA $(\sqrt{ } \mathrm{BSA})$.

To determine the airway lumen and wall outline, the fullwidth half-maximum (FWHM) algorithm was used in 48/169 articles, and graph-cut segmentation was used in 49/169 articles. In 13/169 articles it was unclear which method was used. 43/169 articles used VIDA software, either based on the Apollo or Pulmonary Workstation. Twenty-eight articles used 
Fig. 1 PRISMA flowchart

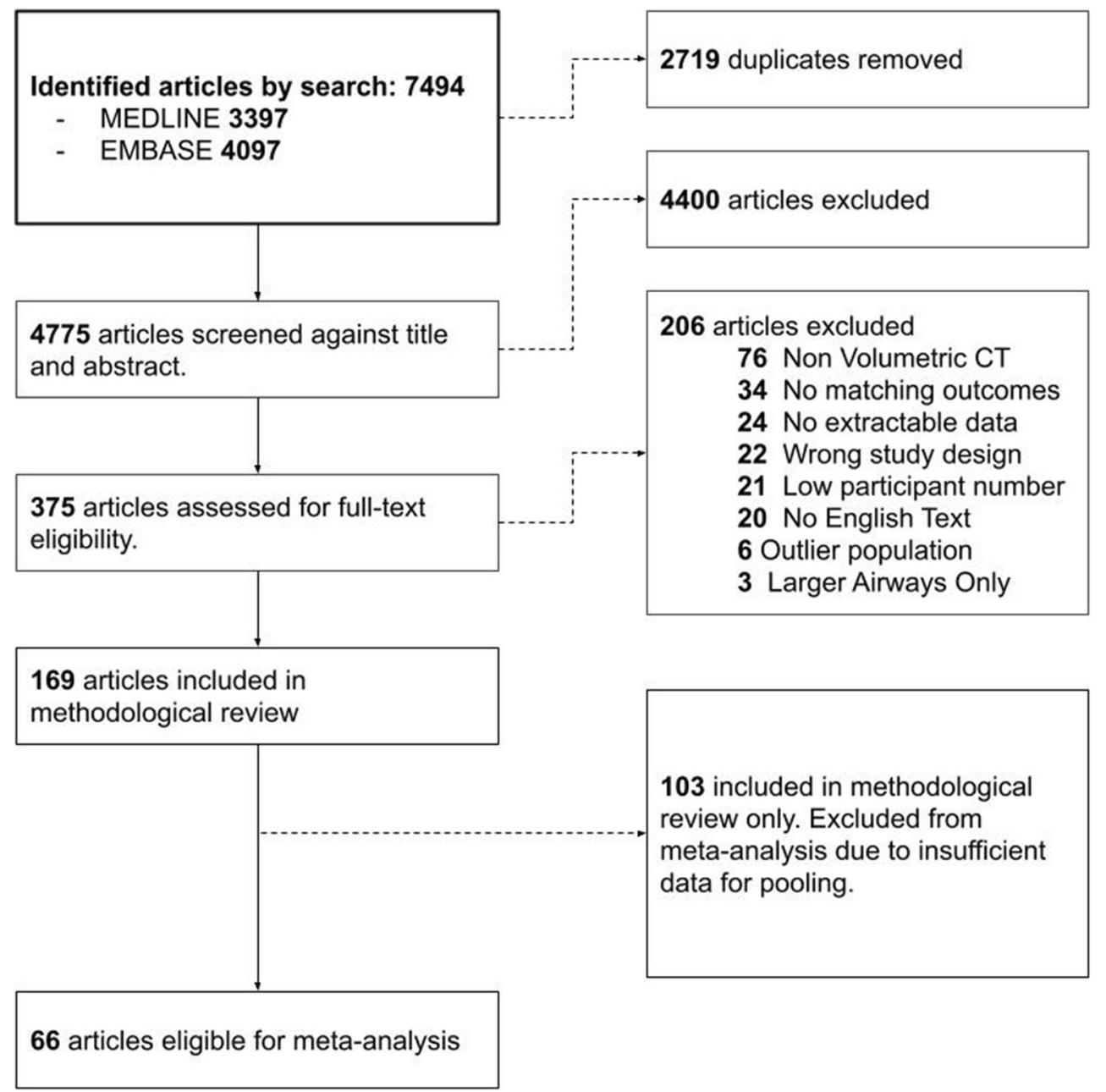

in-house software. The complete summary can be found in Table 2.

\section{Methodologic review-studied airways and generations}

Of the articles that specified which Boyden Classification [36] airway branches were measured, Right Branch (RB)1 and RB10 were measured in $87 / 169$ and $66 / 169$ articles respectively, and Left Branch (LB)1 \pm 2 and LB10 in 77/ 169 and 42/169 articles (Figure 4). Articles were not included when the airway generation was of a mathematical rather than anatomical distinction, i.e. according to Weibel's "A" model of the lung [37]. Out of the included articles, the 3rd generation airway was measured in 100/169 articles. 65/169 studies did not provide information on the airway generations that were measured and 4/169 papers measured airways beyond 4th generation and on.
Fig. 2 Risk of Bias summary for studies included in pooled analysis $(n=66)$

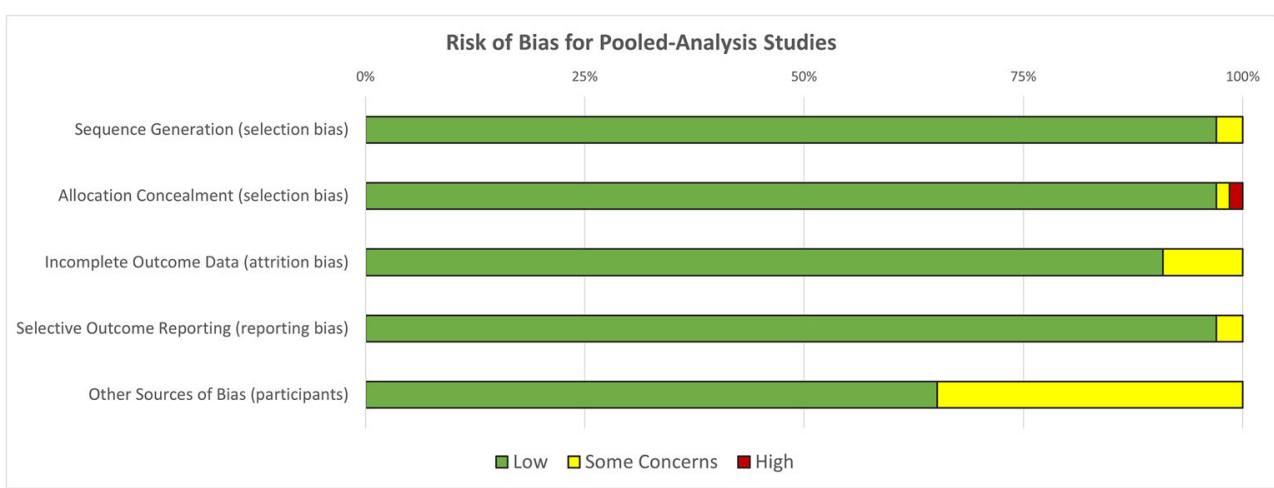


Table 1 Total number of participants across all studies reporting wall area percentage (WA\%), wall area (WA), square root of the wall area of hypothetical airway with internal perimeter of $10 \mathrm{~mm}$ (Pi10), luminal area
(Ai), luminal diameter (Di), and wall thickness (WT). Percentage of participants that are men provided in parentheses. $n$, number of studies

\begin{tabular}{|c|c|c|c|c|c|c|}
\hline & WA $\%$ & WA & Pi10 & $\mathrm{Ai}$ & Di & WT \\
\hline COPD & $\begin{array}{l}11,839(65.7) \\
n=41\end{array}$ & $\begin{array}{l}4,449(64.9) \\
n=16\end{array}$ & $\begin{array}{l}12,746(67.2) \\
n=25\end{array}$ & $\begin{array}{l}9,731(62.3) \\
n=29\end{array}$ & $\begin{array}{l}3,020(69.1) \\
n=10\end{array}$ & $\begin{array}{l}2,919(75.3) \\
n=21\end{array}$ \\
\hline Asthma & $\begin{array}{l}1,856(46.4) \\
n=27\end{array}$ & $\begin{array}{l}1,463(40.8) \\
n=18\end{array}$ & $\begin{array}{l}1,604(43.2) \\
n=9\end{array}$ & $\begin{array}{l}2,634(45.4) \\
n=28\end{array}$ & $\begin{array}{l}712(39.6) \\
n=6\end{array}$ & $\begin{array}{l}1,722(41.5) \\
n=20\end{array}$ \\
\hline Smoking & $\begin{array}{l}9,257(59.5) \\
n=23\end{array}$ & $\begin{array}{l}3,168(60.8) \\
n=9\end{array}$ & $\begin{array}{l}15,092(64.4) \\
n=24\end{array}$ & $\begin{array}{l}3,927(64.5) \\
n=17\end{array}$ & $\begin{array}{l}5,207(61.57) \\
n=9\end{array}$ & $\begin{array}{l}5,062(61.3) \\
n=11\end{array}$ \\
\hline Never-smoking & $\begin{array}{l}965(44.9) \\
n=22\end{array}$ & $\begin{array}{l}378(43.9) \\
n=11\end{array}$ & $\begin{array}{l}898(40) \\
n=9\end{array}$ & $\begin{array}{l}1,303(49) \\
n=22\end{array}$ & $\begin{array}{l}742(45.3) \\
n=7\end{array}$ & $\begin{array}{l}1,127(41.7) \\
n=16\end{array}$ \\
\hline
\end{tabular}

\section{Pooled analysis—-measured bronchial parameters}

Never-smoking populations had the smallest 3rd generation WA\% $(57.53 \pm 8.71 \% n=693)$ followed by smoking populations $(61.2 \pm 6.43 \% n=3,228)$, and asthma populations $(62.04 \pm 7.0 \% n=499)$, with COPD populations having the largest WA\% (62.93 $\pm 7 \% n=6,045)$ (Figure 5). One-way ANOVA analysis for WA\% showed significant differences between all groups except for smoking versus asthma populations $(p=0.07,95 \% \mathrm{CI}[-0.05 \%, 1.7 \%])$ (Table 3 ).

Pi10 pooled analysis indicates that never-smoking populations have a larger Pi10 (3.81 $\pm 0.7 \mathrm{~mm} n=644)$ than smoking populations $(3.23 \pm 0.83 \mathrm{~mm} n=4,942)(p<0.001,95 \%$ CI [ $-0.5 \mathrm{~mm},-0.6 \mathrm{~mm}])$, but smaller than COPD populations $(3.96 \pm 0.55 \mathrm{~mm} n=6,887)(p<0.001,95 \%$ CI $[0.1 \mathrm{~mm}$, $0.2 \mathrm{~mm}]$ ) (Figure 6) while asthma populations had the largest Pi10 $(4.03 \pm 0.27 n=442)(p=<0.001,95 \%$ CI $[0.1 \mathrm{~mm}, 0.3$ $\mathrm{mm}]$ ).

Third generation Ai normalised to BSA was largest in neversmoking populations $\left(12.46 \pm 4 \mathrm{~mm}^{2} n=134\right)$, followed by asthma $\left(10.09 \pm 3.21 \mathrm{~mm}^{2} n=336\right)$, smoking $\left(9.89 \pm 3.96 \mathrm{~mm}^{2}\right.$ $n=108)$, and COPD populations $\left(9.59 \pm 5.49 \mathrm{~mm}^{2} n=712\right)$. With non-normalised Ai, never-smoking had a smaller Ai
(21.69 $\left.\pm 11.15 \mathrm{~mm}^{2} n=192\right)$ compared to smoking (24.09 \pm $\left.12.8 \mathrm{~mm}^{2} n=2,358\right)$, and marginally larger than COPD $(21.45$ $\left.\pm 10.58 \mathrm{~mm}^{2} n=3,323\right)$ and asthma $\left(19.45 \pm 6.77 \mathrm{~mm}^{2} n=\right.$ 161).

WT pooled analysis revealed that never-smoking had the thickest 3rd generation walls $(2.39 \pm 0.83 \mathrm{~mm} n=460)$ compared to smoking $(1.48 \pm 0.16 n=594), \operatorname{COPD}(1.32 \pm 0.34 n$ $=1,254)$, and asthma $(1.36 \pm 0.4 n=163)$.

\section{Meta-analysis of 3rd generation WA\% for COPD vs controls}

Sixteen studies were included in sub analysis of 3rd generation WA\%, 6 with never-smokers as controls and 10 with smokers as controls. Overall, 3rd generation WA\% was $2.78 \%$ larger in COPD compared to controls, $p \leq 0.001$, 95\% CI $[1.85,3.71]$ (Figure S3). Sub-analysis between COPD and never-smokers shows a difference of $2.59 \%$ larger WA\% for COPD, 95\% CI [1.14, 4.05] and between COPD and smokers WA\% was $2.90 \%$ larger in COPD, $95 \% \mathrm{CI}$ $[1.71,4.09]$. Egger's test shows an intercept of 0.35 and $p=$ 0.712 . The $\mathrm{I}^{2}$ ranged from 70.65 to $79.97 \%$ in the subgroups, and overall $87.71 \%$.
Fig. 3 Number of articles investigating a bronchial parameter, with total number of participants per group and across studies indicated by bubble size

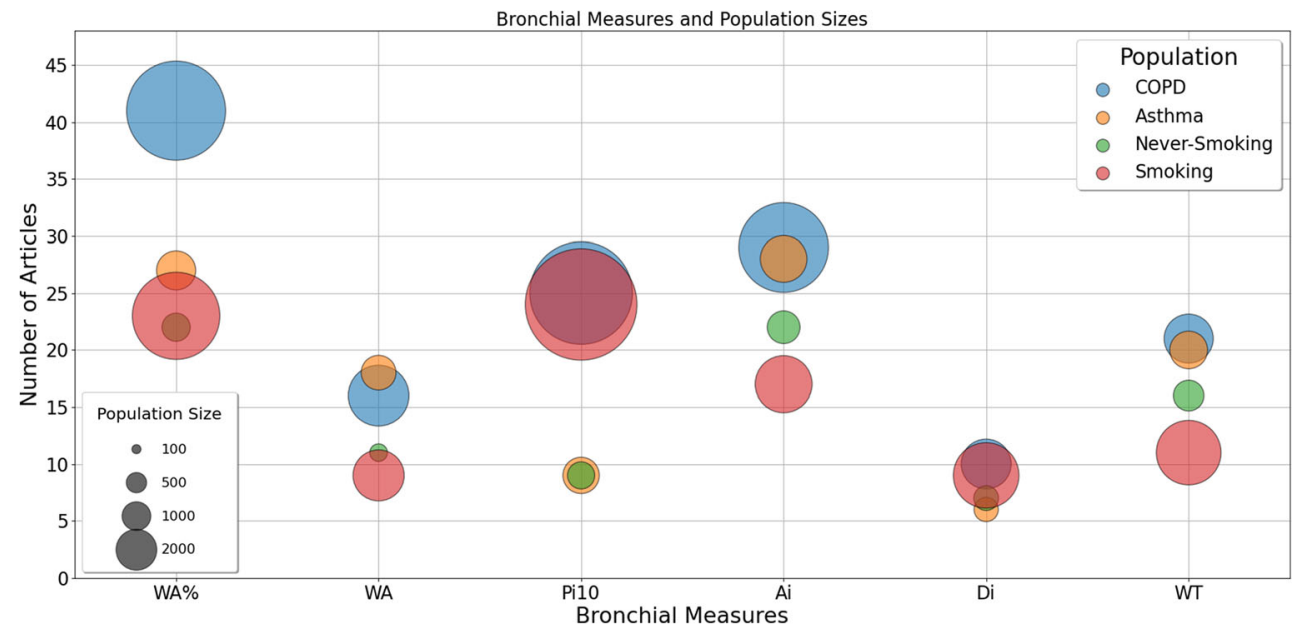


Table 2 Summary of methodology, indicating the number of articles investigating airway generations or lobes, and the algorithms, methods, and software used for bronchial parameter measurement. $N=169$ articles. Most studies analysed more than one airway generation. $F W H M$, full-width half maximum

\begin{tabular}{|c|c|c|c|c|c|c|c|}
\hline \multicolumn{2}{|c|}{$\begin{array}{l}\text { Airway } \\
\text { generations }\end{array}$} & \multicolumn{2}{|c|}{ Analysed by lobe } & \multicolumn{2}{|l|}{ Wall algorithm } & \multicolumn{2}{|l|}{ Software used } \\
\hline 3 & 100 & RUL & 21 & Graph-cut & 49 & In-house & 28 \\
\hline 4 & 77 & LUL & 16 & FWHM & 48 & Apollo VIDA & 25 \\
\hline 5 & 68 & RLL & 14 & Intensity-Integration & 17 & Pulmonary Workstation VIDA & 18 \\
\hline 6 & 44 & LLL & 11 & Unclear & 13 & Airway Inspector 3D Slicer & 10 \\
\hline 7 & 22 & RML & 10 & Manual & 6 & Other & 41 \\
\hline $8+$ & 17 & Lingula & 3 & Other & 8 & Unclear & 19 \\
\hline
\end{tabular}

\section{Discussion}

This systematic review aimed to explore the field of bronchial parameter research in different specified populations. The results show that the study of CT bronchial parameters is biased towards the COPD population's larger airways. Exploration of airways in never-smokers is needed to solidify knowledge on the differences in bronchial parameters due to participant characteristics. Bronchial walls were most often measured using the full-width half-maximum or the graph-cut method on a plane perpendicular to the centreline of the airway, making full use of the utility of a volumetric CT scan. The 3rd generation right upper lobe apical segment branch was the most often measured bronchial parameter. From a subset of studies, we pooled and compared the reported bronchial parameter values for never-smoking, smoking, asthma, and COPD populations. The wall area percentage of the 3 rd generation airway was significantly different between all populations $(p<0.001)$ except between the smoking and asthma populations $(p=0.07)$. The square root of the wall area of a hypothetical airway of $10 \mathrm{~mm}$ was significantly larger in the never-smoking compared to smoking population $(p<0.00195 \%$ CI $[-0.5,-0.6])$.
Bronchial parameter research is heavily focused on the COPD and smoking populations. Low numbers of neversmoking participants limit our baseline knowledge of the normal lung parenchyma and bronchial walls as assessed on CT. Our review showed that articles reporting on never-smoking and asthma populations tended to normalise parameters, while articles investigating smoking and COPD did not. Normalisation seeks to control for patient characteristics that affect bronchial wall parameters. The majority of normalisation is performed with body surface area or square root of body surface area due to the similarity of units [38]. Alternative methods of normalisation, such as normalisation to tracheal parameters, have been examined but may require further research to assess robustness [39-41]. Inclusion of more never-smokers in studies may allow for clearer understanding of the interplay between bronchial parameters and participant characteristics such as sex, height, and age, without the confounding factors of smoking and other disease states.

One of the challenges in conducting research in the field of quantitative CT bronchial parameters is determining the optimal CT methodology for bronchial wall measurement. Scanner model and protocol significantly influence the measurements [42, 43], along with participant inspiration levels during the scan $[44,45]$. CT scanning is continually
Fig. 4 Studied airway branches; grey colour indicates right lung; white colour indicates left lung. Number on $x$ axis indicates branch. $y$ axis indicates number of articles that include a measure of the specified branch

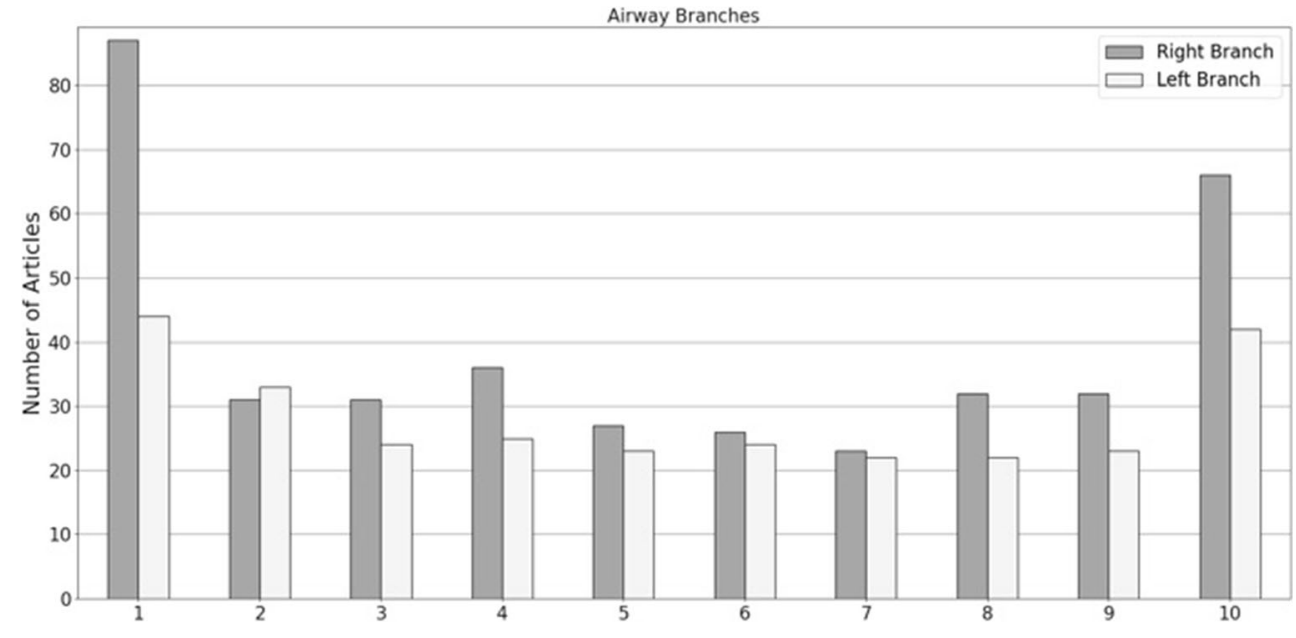


Table $395 \%$ confidence Interval (in square brackets) and $p$ values of one-way ANOVA with Tukey HSD post hoc test comparing the difference between pooled values per population for wall area percentage (WA\%), luminal area (Ai), Ai normalised to body surface area (BSA), square root of the wall area of a hypothetical airway with internal perimeter of $10 \mathrm{~mm}$ (Pi10), and wall thickness (WT)

\begin{tabular}{|c|c|c|c|}
\hline & Smoking & COPD & Asthma \\
\hline \multicolumn{4}{|l|}{ WA\% [\%] } \\
\hline Never-smoking & $\begin{array}{l}{[2.9,4.5]} \\
<0.001\end{array}$ & $\begin{array}{l}{[4.7,6.1]} \\
<0.001\end{array}$ & $\begin{array}{l}{[3.4,5.6]} \\
<0.001\end{array}$ \\
\hline Smoking & & $\begin{array}{l}{[1.3,2.1]} \\
<0.001\end{array}$ & $\begin{array}{l}{[-0.05,1.7]} \\
0.07\end{array}$ \\
\hline COPD & & & $\begin{array}{l}{[-0.03,-1.7]} \\
<0.05\end{array}$ \\
\hline \multicolumn{4}{|l|}{ Pi10 [mm] } \\
\hline Never-smoking & $\begin{array}{l}{[-0.5,-0.6]} \\
<0.001\end{array}$ & $\begin{array}{l}{[0.1,0.2]} \\
<0.001\end{array}$ & $\begin{array}{l}{[0.1,0.3]} \\
<0.001\end{array}$ \\
\hline Smoking & & $\begin{array}{l}{[0.7,0.8]} \\
<0.001\end{array}$ & $\begin{array}{l}{[0.7,0.8]} \\
<0.001\end{array}$ \\
\hline COPD & & & $\begin{array}{l}{[-0.2,0.02]} \\
0.16\end{array}$ \\
\hline \multicolumn{4}{|l|}{ WT [mm] } \\
\hline Never-smoking & $\begin{array}{l}{[-0.9,-1]} \\
<0.001\end{array}$ & $\begin{array}{l}{[-1,-1.1]} \\
<0.001\end{array}$ & $\begin{array}{l}{[-0.9,-1.1]} \\
<0.001\end{array}$ \\
\hline Smoking & & $\begin{array}{l}{[-0.1,-0.2]} \\
<0.001\end{array}$ & $\begin{array}{l}{[-0.01,-0.2]} \\
0.02\end{array}$ \\
\hline COPD & & & $\begin{array}{l}{[-0.06,0.1]} \\
0.8\end{array}$ \\
\hline \multicolumn{4}{|l|}{$\mathrm{Ai}\left[\mathrm{mm}^{2}\right]$} \\
\hline Never-smoking & $\begin{array}{l}{[0.2,4.6]} \\
0.03\end{array}$ & $\begin{array}{l}{[-1.9,2.4]} \\
0.98\end{array}$ & $\begin{array}{l}{[-5.4,0.9]} \\
0.26\end{array}$ \\
\hline Smoking & & $\begin{array}{l}{[-1.8,-3.4]} \\
<0.001\end{array}$ & $\begin{array}{l}{[-2.2,-7]} \\
<0.001\end{array}$ \\
\hline COPD & & & $\begin{array}{l}{[-4.4,0.4]} \\
0.13\end{array}$ \\
\hline \multicolumn{4}{|l|}{$\mathrm{Ai} / \mathrm{BSA}\left[\mathrm{mm}^{2}\right]$} \\
\hline Never-smoking & $\begin{array}{l}{[0.9,4.1]} \\
<0.001\end{array}$ & $\begin{array}{l}{[-1.7,-4]} \\
<0.001\end{array}$ & $\begin{array}{l}{[-1.1,-3.6]} \\
<0.001\end{array}$ \\
\hline Smoking & & $\begin{array}{l}{[-1.6,0.9]} \\
0.92\end{array}$ & $\begin{array}{l}{[-1.1,1.5]} \\
0.98\end{array}$ \\
\hline COPD & & & $\begin{array}{l}{[-0.3,1.3]} \\
0.37\end{array}$ \\
\hline
\end{tabular}

advancing, and much of the early research has been focused on individual slices where the airway is cut in cross section according to anatomical properties, e.g. the right upper lobe apical segment airway being almost perpendicular in the axial plane. However, volumetric scanning is increasingly more common and allows for segmentation of the airway tree, in turn allowing for more accurate measurement of the walls. Most articles using volumetric CT scanning employed multiplanar reconstruction when measuring airways, a method that unlocks more bronchial branches for measurement. Despite this, we identified that the larger airways in the upper and lower lobes of the lungs were most often studied; relying on a single location may not adequately capture the complex structural changes that the lungs undergo in disease (e.g. upper vs lower airways [46]). Access to cheap computing allows more complex segmentation and wall measuring tools; however, most articles use FWHM which has been shown by Gierada et. al and Washko et al. to over-estimate the wall thickness [15, 47].

WA\% was by far the most measured parameter within all populations and 3rd generation WA\% was significantly different between all except smoking versus asthma populations. The meta-analysis focusing on the COPD population vs controls supports the results of the pooled analysis, showing significantly increased WA\% in the COPD population. Egger's test and the funnel plot demonstrate no strong evidence for publication bias for this bronchial parameter. The analysis displayed heterogeneity which was not resolved when the sub-groups were analysed; this indicates that the heterogeneity does not stem from a difference in the populations. Overall $3 \mathrm{rd}$ generation WA\% appears to be a robust parameter when used to differentiate COPD subjects to controls, despite considerable heterogeneity in the data which may stem from differences in methodology.

Pi10 was distinctly explored in COPD and smoking populations, and less so in asthma and the neversmoking populations. Pooled analysis of bronchial parameters shows significant differences between populations despite different measurement methodologies however with a considerable overlap between the ranges of populations. Pooled Ai normalised to BSA had a smaller range than non-normalised $\mathrm{Ai}$ and in both cases the numbers in pooled analyses were low. This may indicate that direct measures are not specific enough to discern between groups, as other participant/pathologic processes play a role in Ai, for example height and sex. Direct measures of bronchial parameters are important building blocks; however, derived markers are more likely to be robust as they correct for confounding factors.

We noted that the pooled values of Pi10 and WT were larger in the never-smoking population compared to smokers, and smaller compared to COPD participants, due to differences of Pi10 measurements in some of the larger studies compared to the others. This was an unexpected finding as current literature indicates that never-smoking individuals have less airway inflammation than smoking, COPD, and asthma populations. The high Pi10 measurement in some studies may be due to several factors. First, Pi10 is calculated by plotting a regression line based on several airway measurements; the location and method of measurements may strongly influence the slope and intercept, leading to differing results $[48,49]$. Second, there were more Asian participants in the never-smoking pooled value of Pi10. Ethnicity may play a role and differences between Asian and Caucasian 
Fig. 5 Pooled analysis of (a) percentage wall area (WA\%) of 3rd generation airways, (b) square root of the wall area of hypothetical airway of internal perimeter of 10mm (Pi10), (c) luminal area (Ai) normalised to body surface area (BSA), (d) wall thickness (WT) of 3rd generation airways. Diamond location is the mean; size indicates relative number of included participants. Error bars are standard deviation
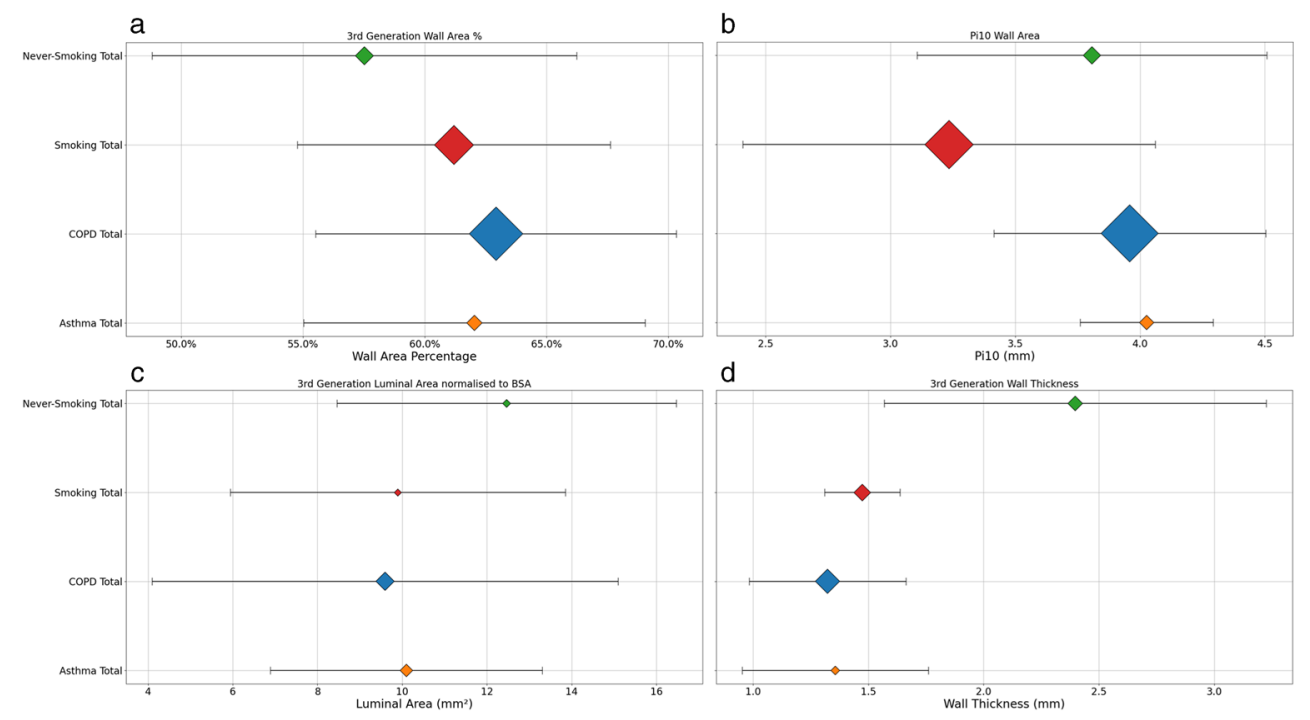

populations have been demonstrated in previous studies [50]. Thirdly, the smoking and COPD populations were predominantly older men with a larger number of participants, while never-smoking populations tended to be younger and included more women. As previous studies have shown, these characteristics play a role in bronchial parameters [51-55]. We were not able to identify suitable measurements to include in the pooled analysis for never-smoking from all studies; however, COPDGene noted a Pi10 of $1.69 \pm 0.23 \mathrm{~mm}$ in 44 neversmoking individuals [56], which is much lower than the pooled analysis total. This suggests that while Pi10 may be consistent within a study, differences in the methods used to calculate it may not allow for confident comparison between studies.

\section{Limitations}

This study had several limitations. First, the pooled analysis could only include reported means and standard deviations, which assumes a normal distribution in the populations but may not reflect the true distribution. Second, due to the lack of a detailed breakdown of participants in most reviewed
Fig. 6 Pooled analysis of square root of wall area of hypothetical airway with internal perimeter of $10 \mathrm{~mm}$ (Pi10) in never-smoking (A) and Smoking (B) populations. Values are mean \pm SD with diamond size indicating relative number of included participants

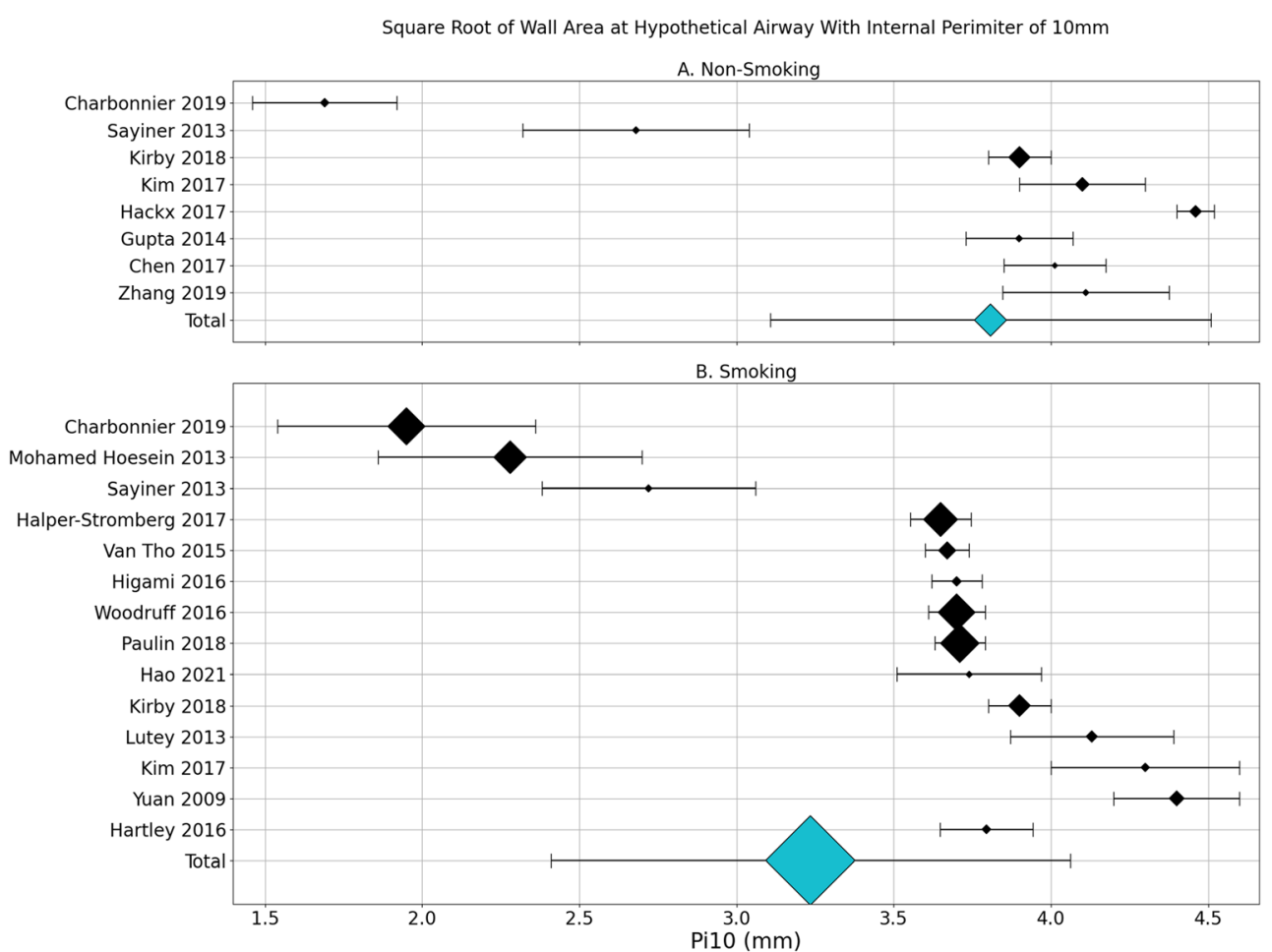


literature, it was not possible to perform pooled analysis of sub-groups, and so the pooled values include both men and women, and a wide range of ages, disease states (e.g. nonsevere and severe asthma, or GOLD I-IV COPD), and backgrounds (Caucasian, Asian, African-American). Finally, while there are multiple novel potential bronchial parameters emerging due to advancing computation and automation, such as airway tapering and total airway count [57-61], we were able to focus only on the parameters that were available for data extraction. Lastly, of the papers included for meta-analysis, only one obtained post-bronchodilation CT measurements [57]. While post-bronchodilator pulmonary function testing was the norm for studies utilising this technique, it was not used during the CT scan, indicating a difference between the acquisition of spirometry and the $\mathrm{CT}$.

\section{Conclusions}

There are significant differences in bronchial parameters between populations, most notably in the wall area percentage of the 3rd generation airway; however, there is a large overlap in their ranges. While previous studies demonstrate that Pi10 can differentiate disease states within a study, our analysis indicates it may not be a robust parameter when comparing different studies. A paucity of never-smoking participants, along with heterogenous wall measurement methodology, may explain the diverging results from studies on the influence of participant characteristics in bronchial parameters.

Supplementary Information The online version contains supplementary material available at https://doi.org/10.1007/s00330-022-08600-1.

Funding This study is part of the first author's $\mathrm{PhD}$ which has received funding by IMDI (Innovative Medical Devices Initiative)/ZonMW (Netherlands Organisation for Health Research and Development.

\section{Declarations}

Guarantor The scientific guarantor of this publication is Prof. Rozemarijn Vliegenthart.

Conflict of interest The authors declare no competing interests.

Statistics and biometry One of the authors has significant statistical expertise.

Informed consent Informed consent was not required for this study.

Ethical approval Institutional Review Board approval was not required.

\section{Methodology}

- Systematic review

- Meta-analysis
Open Access This article is licensed under a Creative Commons Attribution 4.0 International License, which permits use, sharing, adaptation, distribution and reproduction in any medium or format, as long as you give appropriate credit to the original author(s) and the source, provide a link to the Creative Commons licence, and indicate if changes were made. The images or other third party material in this article are included in the article's Creative Commons licence, unless indicated otherwise in a credit line to the material. If material is not included in the article's Creative Commons licence and your intended use is not permitted by statutory regulation or exceeds the permitted use, you will need to obtain permission directly from the copyright holder. To view a copy of this licence, visit http://creativecommons.org/licenses/by/4.0/.

\section{References}

1. Reitsma MB, Fullman N, Ng M et al (2017) Smoking prevalence and attributable disease burden in 195 countries and territories, 1990-2015: a systematic analysis from the Global Burden of Disease Study 2015. Lancet 389:1885-1906. https://doi.org/10. 1016/S0140-6736(17)30819-X

2. Quaderi SA, Hurst JR (2018) The unmet global burden of COPD. Glob Health Epidemiol Genom 3. https://doi.org/10.1017/gheg. 2018.1

3. Ehteshami-Afshar S, FitzGerald JM, Doyle-Waters MM, Sadatsafavi M (2016) The global economic burden of asthma and chronic obstructive pulmonary disease. Int J Tuberc Lung Dis 20: 11-23. https://doi.org/10.5588/ijtld.15.0472

4. Shimizu K, Hasegawa M, Makita H et al (2011) Comparison of airway remodelling assessed by computed tomography in asthma and COPD. Respir Med 105:1275-1283. https://doi.org/10.1016/j. rmed.2011.04.007

5. Patel BD, Coxson HO, Pillai SG et al (2008) Airway wall thickening and emphysema show independent familial aggregation in chronic obstructive pulmonary disease. Am J Respir Crit Care Med 178:500-505. https://doi.org/10.1164/rccm.200801-059OC

6. Lynch DA, Austin JHM, Hogg JC et al (2015) CT-definable subtypes of chronic obstructive pulmonary disease: a statement of the Fleischner Society. Radiology 277:192-205. https://doi.org/10. 1148/radiol.2015141579

7. Ross JC, Castaldi PJ, Cho MH et al (2018) Longitudinal modeling of lung function trajectories in smokers with and without chronic obstructive pulmonary disease. Am J Respir Crit Care Med 198: 1033-1042. https://doi.org/10.1164/rccm.201707-1405OC

8. Oelsner EC, Ortega VE, Smith BM et al (2019) A genetic risk score associated with chronic obstructive pulmonary disease susceptibility and lung structure on computed tomography. Am J Respir Crit Care Med 200:721-731. https://doi.org/10.1164/rccm.201812$2355 \mathrm{OC}$

9. Dijkstra AE, Postma DS, van Ginneken B et al (2015) Novel genes for airway wall thickness identified with combined genome-wide association and expression analyses. Am J Respir Crit Care Med 191:547-556. https://doi.org/10.1164/rccm.201405-0840OC

10. Hoshino M, Ohtawa J (2012) Effects of budesonide/formoterol combination therapy versus budesonide alone on airway dimensions in asthma. Respirology 17:639-646. https://doi.org/10.1111/ j.1440-1843.2012.02130.x

11. Li Y, Dai Y, Guo Y (2018) The pulmonary damage caused by smoking: a longitudinal study. Technol Health Care 26:501-507. https://doi.org/10.3233/THC-174800

12. Takayanagi S, Kawata N, Tada Y et al (2017) Longitudinal changes in structural abnormalities using MDCT in COPD: do the CT measurements of airway wall thickness and small pulmonary vessels change in parallel with emphysematous progression? Int J Chron 
Obstruct Pulmon Dis 12:551-560. https://doi.org/10.2147/COPD. S121405

13. Liu L, Li G, Sun Y et al (2015) Airway wall thickness of allergic asthma caused by weed pollen or house dust mite assessed by computed tomography. Respir Med 109:339-346. https://doi.org/ 10.1016/j.rmed.2014.11.011

14. Thomson NC, Chaudhuri R, Spears M et al (2015) Poor symptom control is associated with reduced CT scan segmental airway lumen area in smokers with asthma. Chest 147:735-744. https://doi.org/ 10.1378/chest.14-1119

15. Gierada DS, Guniganti P, Newman BJ et al (2011) Quantitative CT assessment of emphysema and airways in relation to lung cancer risk. Radiology 261:950-959. https://doi.org/10.1148/radiol. 11110542

16. Ji W, Lim MN, Bak SH et al (2018) Differences in chronic obstructive pulmonary disease phenotypes between non-smokers and smokers. Clin Respir J 12:666-673. https://doi.org/10.1111/crj. 12577

17. Kirby M, Pike D, Sin DD et al (2015) COPD: do imaging measurements of emphysema and airway disease explain symptoms and exercise capacity? Radiology 277:872-880. https://doi.org/10. 1148/radiol.2015150037

18. Lowe KE, Regan EA, Anzueto A, et al (2019) COPDGene(®) 2019: redefining the diagnosis of chronic obstructive pulmonary disease. Chronic Obstr Pulm Dis 6:384-399. 10.15326/ jcopdf.6.5.2019.0149

19. Diaz AA, Bartholmai B, San José Estépar R et al (2010) Relationship of emphysema and airway disease assessed by CT to exercise capacity in COPD. Respir Med 104:1145-1151. https://doi.org/10.1016/j.rmed.2010.02.023

20. Higami Y, Ogawa E, Ryujin Y et al (2016) Increased epicardial adipose tissue is associated with the airway dominant phenotype of chronic obstructive pulmonary disease. PLoS One 11:e0148794 e0148794. https://doi.org/10.1371/journal.pone.0148794

21. Mohamed Hoesein FAA, Schmidt M, Mets OM et al (2014) Discriminating dominant computed tomography phenotypes in smokers without or with mild COPD. Respir Med 108:136-143. https://doi.org/10.1016/j.rmed.2013.08.014

22. Koyama H, Ohno Y, Yamazaki Y et al (2012) Quantitative bronchial luminal volumetric assessment of pulmonary function loss by thin-section MDCT in pulmonary emphysema patients. Eur J Radiol 81:384-388. https://doi.org/10.1016/j.ejrad.2010.12.042

23. Hackx M, Francotte D, Garcia TS et al (2017) Effect of total lung capacity, gender and height on CT airway measurements. BJR 90: 20160898. https://doi.org/10.1259/bjr.20160898

24. Diaz AA, Han MK, Come CE et al (2013) Effect of emphysema on CT scan measures of airway dimensions in smokers. Chest 143: 687-693. https://doi.org/10.1378/chest.12-0039

25. Gietema HA, Edwards LD, Coxson HO et al (2013) Impact of emphysema and airway wall thickness on quality of life in smoking-related COPD. Respir Med 107:1201-1209. https://doi. org/10.1016/j.rmed.2013.04.016

26. Hong Y, Ji W, An S et al (2016) Sex differences of COPD phenotypes in nonsmoking patients. Int J Chron Obstruct Pulmon Dis 11: 1657-1662. https://doi.org/10.2147/COPD.S108343

27. Zach JA, Newell JD, Schroeder J et al (2012) Quantitative computed tomography of the lungs and airways in healthy nonsmoking adults. Invest Radiol 47:596-602. https://doi.org/10.1097/RLI. 0b013e318262292e

28. Kim Y-I, Schroeder J, Lynch D et al (2011) Gender differences of airway dimensions in anatomically matched sites on CT in smokers. COPD 8:285-292. https://doi.org/10.3109/15412555.2011.586658

29. Washko GR, Parraga G (2018) COPD biomarkers and phenotypes: opportunities for better outcomes with precision imaging. Eur Respir J 52:1801570. https://doi.org/10.1183/13993003.015702018
30. Moher D, Liberati A, Tetzlaff J et al (2009) Preferred reporting items for systematic reviews and meta-analyses: the PRISMA statement. PLoS Med 6:e1000097. https://doi.org/10.1371/journal. pmed.1000097

31. Covidence - Better systematic review management. In: Covidence. https://www.covidence.org/. Accessed 7 Aug 2020

32. Sterne JAC, Savović J, Page MJ et al (2019) RoB 2: a revised tool for assessing risk of bias in randomised trials. BMJ:366. https://doi. org $/ 10.1136 /$ bmj. 14898

33. Cochrane Formulae for combining groups. https://training. cochrane.org/handbook/current/chapter-06\#section-6-5-2-10. Accessed 15 Aug 2021

34. Larson DA (2012) Analysis of variance with just summary statistics as input. The American Statistician 46:2,151-152. https://doi.org/ 10.1080/00031305.1992.10475872

35. Egger M, Davey Smith G, Schneider M, Minder C (1997) Bias in meta-analysis detected by a simple, graphical test. BMJ 315:629634. https://doi.org/10.1136/bmj.315.7109.629

36. Boyden EA (1953) A critique of the international nomenclature on bronchopulmonary segments. Dis Chest 23:266-269. https://doi. org/10.1378/chest.23.3.266

37. Weibel ER (1963) Morphometry of the human lung. SpringerVerlag, Berlin Heidelberg

38. Nakano Y, Muro S, Sakai H et al (2000) Computed tomographic measurements of airway dimensions and emphysema in smokers. Correlation with lung function. Am J Respir Crit Care Med 162: 1102-1108. https://doi.org/10.1164/ajrccm.162.3.9907120

39. Choi S, Hoffman EA, Wenzel SE et al (2015) Quantitative assessment of multiscale structural and functional alterations in asthmatic populations. J Appl Physiol (1985) 118:1286-1298. https://doi.org/ 10.1152/japplphysiol.01094.2014

40. Choi S, Haghighi B, Choi J et al (2017) Differentiation of quantitative $\mathrm{CT}$ imaging phenotypes in asthma versus COPD. BMJ Open Respir Res 4:e000252-e000252. https://doi.org/10.1136/bmjresp2017-000252

41. Haghighi B, Choi S, Choi J et al (2019) Imaging-based clusters in former smokers of the COPD cohort associate with clinical characteristics: the SubPopulations and intermediate outcome measures in COPD study (SPIROMICS). Respir Res 20:153-153. https://doi. org/10.1186/s12931-019-1121-Z

42. Subramanian DR, Gupta S, Burggraf D et al (2016) Emphysemaand airway-dominant COPD phenotypes defined by standardised quantitative computed tomography. Eur Respir J 48:92-103. https://doi.org/10.1183/13993003.01878-2015

43. Koyama $\mathrm{H}$, Ohno $\mathrm{Y}$, Nishio $\mathrm{M}$ et al (2014) Iterative reconstruction technique vs filter back projection: utility for quantitative bronchial assessment on low-dose thin-section MDCT in patients with/ without chronic obstructive pulmonary disease. Eur Radiol 24: 1860-1867. https://doi.org/10.1007/s00330-014-3207-9

44. Petersen J, Wille MMW, Rakêt LL et al (2014) Effect of inspiration on airway dimensions measured in maximal inspiration CT images of subjects without airflow limitation. Eur Radiol 24:2319-2325. https://doi.org/10.1007/s00330-014-3261-3

45. Kambara K, Shimizu K, Makita H et al (2014) Effect of lung volume on airway luminal area assessed by computed tomography in chronic obstructive pulmonary disease. PLoS One 9:e90040 e90040. https://doi.org/10.1371/journal.pone.0090040

46. Gupta S, Hartley R, Khan UT et al (2014) Quantitative computed tomography-derived clusters: redefining airway remodeling in asthmatic patients. J Allergy Clin Immunol 133:729-38.e18. https:// doi.org/10.1016/j.jaci.2013.09.039

47. Washko GR, Dransfield MT, Estépar RSJ et al (2009) Airway wall attenuation: a biomarker of airway disease in subjects with COPD. J Appl Physiol (1985) 107:185-191. https://doi.org/10.1152/ japplphysiol.00216.2009 
48. Schmidt M, Kuhnigk J-M, Krass S et al (2010) Reproducibility of airway wall thickness measurements. In: Karssemeijer N, Summers RM (eds) San Diego. California, USA, p 762410

49. Lutey BA, Conradi SH, Atkinson JJ et al (2013) Accurate measurement of small airways on low-dose thoracic CT scans in smokers. Chest 143:1321-1329. https://doi.org/10.1378/chest.12-0034

50. Cho HB, Chae KJ, Jin GY et al (2019) Structural and functional features on quantitative chest computed tomography in the Korean Asian versus the White American healthy non-smokers. Korean J Radiol 20:1236-1245. https://doi.org/10.3348/kjr.2019.0083

51. Hansel NN, Washko GR, Foreman MG et al (2013) Racial differences in CT phenotypes in COPD. COPD 10:20-27. https://doi. org/10.3109/15412555.2012.727921

52. Wan ES, Hokanson JE, Murphy JR et al (2011) Clinical and radiographic predictors of GOLD-unclassified smokers in the COPDGene study. Am J Respir Crit Care Med 184:57-63. https://doi.org/10.1164/rccm.201101-0021OC

53. Inoue H, Niimi A, Takeda T et al (2014) Pathophysiological characteristics of asthma in the elderly: a comprehensive study. Ann Allergy Asthma Immunol 113:527-533. https://doi.org/10.1016/j. anai.2014.08.002

54. Kim SS, Jin GY, Li YZ et al (2017) CT quantification of lungs and airways in normal Korean subjects. Korean J Radiol 18:739. https:// doi.org/10.3348/kjr.2017.18.4.739

55. Li Y, Dai Y-L, Yu N, Guo Y-M (2018) Sex-related differences in bronchial parameters and pulmonary function test results in patients with chronic obstructive pulmonary disease based on threedimensional quantitative computed tomography. J Int Med Res 46:135-142. https://doi.org/10.1177/0300060517721309
56. Charbonnier J-P, Pompe E, Moore C et al (2019) Airway wall thickening on CT: relation to smoking status and severity of COPD. Respir Med 146:36-41. https://doi.org/10.1016/j.rmed. 2018.11.014

57. Eddy RL, Svenningsen S, Kirby M et al (2020) Is computed tomography airway count related to asthma severity and airway structure-function? Am J Respir Crit Care Med. https://doi.org/10.1164/ rccm.201908-1552OC

58. Oguma T, Hirai T, Fukui M et al (2015) Longitudinal shape irregularity of airway lumen assessed by $\mathrm{CT}$ in patients with bronchial asthma and COPD. Thorax 70:719-724. https://doi.org/10.1136/ thoraxjnl-2014-206651

59. Tanabe N, Sato S, Oguma T et al (2019) Associations of airway tree to lung volume ratio on computed tomography with lung function and symptoms in chronic obstructive pulmonary disease. Respir Res 20:77-77. https://doi.org/10.1186/s12931-019-1047-5

60. Bodduluri S, Puliyakote ASK, Gerard SE et al (2018) Airway fractal dimension predicts respiratory morbidity and mortality in COPD. J Clin Invest 128:5374-5382. https://doi.org/10.1172/ JCI120693

61. Smith BM, Hoffman EA, Rabinowitz D et al (2014) Comparison of spatially matched airways reveals thinner airway walls in COPD. The Multi-Ethnic Study of Atherosclerosis (MESA) COPD Study and the Subpopulations and Intermediate Outcomes in COPD Study (SPIROMICS). Thorax 69:987-996. https://doi.org/10. 1136/thoraxjnl-2014-205160

Publisher's note Springer Nature remains neutral with regard to jurisdictional claims in published maps and institutional affiliations. 